\title{
Clube de ciências na formação inicial de professores de química
}

\author{
Science club in chemistry preservice teacher training \\ Clube de ciencias en la formación inicial de profesores de química
}

\author{
Jackson Gois ${ }^{2}$ \\ Juliana Delucia ${ }^{3}$
}

\begin{abstract}
Resumo: Este relato teve por objetivo analisar como a participação de alunos de licenciatura em Química em atividades de um Clube de Ciências contribuiu para sua formação inicial. Focaram-se os relatos escritos dos estudantes de licenciatura em Química sobre como a elaboração e a aplicação de atividades de ensino agregaram para sua própria formação docente. Os licenciandos participaram da elaboração e aplicação de atividades de ensino em 16 reuniões de um Clube de Ciências de uma escola pública localizada em São José do Rio Preto, interior de São Paulo. A partir de uma perspectiva sociocultural, os excertos dos relatos evidenciam que aspectos emocionais positivos resultantes da participação dos licenciandos nas atividades no Clube de Ciências são fundamentais para a formação inicial. Além disso, os licenciandos também apontaram aspectos qualitativos diferenciados na interação com os estudantes de ensino básico como elemento central para sua formação e também como poderiam utilizar melhor as atividades de experimentação. Evidencia-se que as atividades em Clubes de Ciências possibilitam vivências singulares que também viabilizam a formação inicial de professores de Química.
\end{abstract}

Palavras-chave: Clubes de ciências. Formação inicial de professores. Educação em química.

Abstract: This report aimed to analyze how the participation of pre-service Chemistry teachers in activities of a Science Club can contribute to their initial training. The focus was based on the written reports of pre-service Chemistry teachers on how the design and application of teaching activity contributed to their own teacher training. The undergraduates participated in the elaboration and application of teaching activities in 16 meetings of a Science Club of a public school located in São José do Rio Preto, in the interior of São Paulo. From a sociocultural perspective, excerpts from the reports show that positive emotional aspects resulting from the participation of the undergraduates in the activities of the Science Club are fundamental for the initial formation. In addition, the undergraduates also pointed out qualitative aspects differentiated in the interaction with the students of basic education like central element for its formation, and also how they could make better use of the experimental activities. It is evident that the activities in Science Clubs make possible unique experiences that also make possible the initial formation of professors of Chemistry.

Keywords: Science clubs. Preservice teacher training. Chemistry education.

Resumen: Este relato tuvo por objetivo analizar cómo la participación de alumnos de licenciatura en Química en actividades de un Club de Ciencias puede contribuir a su formación inicial. El enfoque se basó en los relatos escritos de los estudiantes de licenciatura en Química sobre cómo la elaboración y aplicación de actividades de enseñanza contribuyó a su propia formación docente. Los licenciandos participaron en la elaboración y aplicación de actividades de enseñanza en 16 reuniones de un Club de Ciencias de una escuela pública ubicada en São José do Rio Preto, interior de São Paulo. A partir de una perspectiva sociocultural, los extractos de los relatos evidencian que aspectos emocionales positivos resultantes de la participación de los licenciandos en las actividades en el Club de Ciencias son fundamentales para la formación inicial. Además, los licenciandos también apuntaron aspectos cualitativos diferenciados en la interacción con los estudiantes de enseñanza básica como elemento central para su formación, y también cómo podrían utilizar mejor las actividades de

\footnotetext{
${ }^{1}$ Submetido em: 18 fev. 2019 - Aceito em: 30 jun. 2019 - Publicado em: 31 maio 2020

2 Universidade Estadual Paulista "Júlio de Mesquita Filho" (UNESP) - E-mail: jgoiss@ gmail.com

${ }^{3}$ Universidade Estadual Paulista "Júlio de Mesquita Filho" (UNESP) - E-mail: julianadelucia@ yahoo.com.br
} 
experimentación. Se evidencia que las actividades en Clubes de Ciencias posibilitan vivencias singulares que también viabilizan la formación inicial de profesores de Química.

Palabras clave: Club de ciencias. Formación inicial de profesores. Educación en química.

\section{Introdução}

Os saberes próprios da profissão docente ganham destaque dentre os diversos temas ligados à formação inicial de professores, o que inclui conhecimentos, competências, habilidades e atitudes (TARDIF, 2002). Nesse sentido, a integração entre as diversas dimensões que contribuem para a construção desses saberes, como as sociais, afetivas e cognitivas, deve ser um objetivo no trabalho de formação inicial docente (GATTI, 2016). Os estudos sobre formação de professores de Química têm procurado contribuir para a reflexão crítica sobre esses processos formativos. Pesquisas mostram que a formação inicial em cursos de licenciatura em Química pode ser considerada como um importante foco de investigação (SILVA; QUEIROZ, 2017).

Parte significativa da formação inicial de professores de Química é possibilitar o uso de ferramentas necessárias para o exercício pleno dos saberes docentes por parte de licenciandos. Nesse sentido, ganha relevância a compreensão sobre como licenciandos em Química aprendem a exercitar esses saberes em estratégias de ensino. Muitas dificuldades enfrentadas por professores iniciantes em Química se relacionam com a utilização de estratégias de ensino em sala de aula (COLOMBO JUNIOR, 2009), uma vez que decisões equivocadas de abordagens por parte do professor podem dificultar o processo de ensino e aprendizagem (SANTOS; MORTIMER, 1999).

\section{Importância de Clubes de Ciências}

A utilização de atividades no formato de Clubes de Ciências é bem conhecida na literatura sobre divulgação científica, uma vez que ajuda o aluno de ensino básico a desenvolver pensamento crítico e capacidade de relacionar o conhecimento científico ao cotidiano. A maior parte dos trabalhos sobre Clubes de Ciências aponta para a necessidade desse tipo de atividade a partir da perspectiva dos ganhos de aprendizagem por parte de alunos de ensino básico.

Prá e Tomio (2014) revisam a literatura sobre o tema dos Clubes de Ciências na área de Educação em Ciências. Os autores abrangem trabalhos publicados até o ano de 2012 no formato de artigos em revistas científicas ("Investigações em Ensino de Ciências", "Ensaio", "Ciência e Educação", "Ciência e Ensino", "Revista Brasileira de Pesquisa em Ensino de Ciências", "Revista Alexandria" e "Ensaio - Pesquisa em Educação em Ciências"), artigos dos Encontros Nacionais de Pesquisa em Ensino de Ciências (ENPEC) de 1997 a 2011 (o evento só ocorre em anos ímpares), teses e dissertações disponíveis no repositório da CAPES ${ }^{\mathrm{i}}$ até 2012 e artigos obtidos com a ferramenta de busca Google Acadêmicoii 
Prá e Tomio (2014) analisaram os trabalhos sob o ponto de vista da distribuição cronológica, origem das pesquisas, modalidades de investigação, participantes investigados e os autores mais citados, dentre outros tópicos. Para o nosso trabalho, destacamos os resultados obtidos na categoria "participantes pesquisados", os quais mostramos na tabela 1. Nesse caso, os autores apontam que em 53\% dos casos (soma das ocorrências de estudantes dos anos iniciais do ensino fundamental, estudantes dos anos finais do ensino fundamental e estudantes de ensino médio) os estudos direcionam o foco para alunos de ensino básico, e apenas $21 \%$ focam estudantes de ensino superior de cursos de licenciatura.

Tabela 1. Participantes pesquisados na revisão de literatura sobre Clubes de Ciências apresentada por Prá e Tomio (2014).

\begin{tabular}{lc}
\hline Sujeitos investigados na pesquisa & Ocorrência \\
\hline Estudantes de Ensino Fundamental - anos iniciais & $18 \%$ \\
Estudantes de Ensino Fundamental - anos finais & $21 \%$ \\
Estudantes de Ensino Médio & $14 \%$ \\
Estudantes de Ensino Superior de cursos de Licenciatura & $21 \%$ \\
Professores de escolas que têm Clubes & $10 \%$ \\
Participantes não identificados & $16 \%$ \\
\hline Fonte: Prá e Tomio (2014)
\end{tabular}

Como exemplos de trabalhos que focalizam alunos de ensino básico, podemos apontar o de Ribeiro e Parente (2006), no qual descrevem a experiência de um Clube de Ciências ligado à Universidade Federal do Pará (UFPA), a partir do ponto de vista das narrativas de alunos de nove a 13 anos, provenientes de escolas públicas dos bairros próximos à universidade. Também há o trabalho de Oliveira (2010), em que se apresenta o processo de alfabetização científica por meio da tomada de notas e de entrevistas com alunos de sete a dez anos de idade de um colégio privado em São Leopoldo - Rio Grande do Sul (RS).

De maneira semelhante, Schleich e colaboradores (2014) apresentam uma pesquisa a partir das produções textuais de estudantes de $5^{\circ}$ e $6^{\circ}$ anos do ensino básico de um colégio privado da cidade de Porto Alegre (RS), utilizando como tema as geotecnologias para estudos no meio ambiente. Silva, Santos e Rôças (2016) investigam a possível redução do estereótipo acerca do trabalho científico em atividades de um Clube de Ciências por meio de questionários aplicados a alunos entre o $7^{\circ}$ e o $9^{\circ}$ ano do ensino fundamental.

É importante também mencionar o trabalho de Parente e colaboradores (2010), que narra as atividades de um Clube de Ciências feitas em parceria entre a UFPA e a Secretaria de Educação do Estado do Pará, em que se apresentou um processo de investigação científica a alunos do $1^{\circ}$ e $2^{\circ}$ anos do ensino fundamental com o tema da erosão. Por sua vez, Alves e colaboradores (2012) apresentam os sentidos subjetivos que afetam a motivação de alunos dos anos finais do ensino fundamental e médio para participar das atividades promovidas no Clube de Ciências.

Também há trabalhos na literatura sobre Clubes de Ciências que procuram analisar as concepções de professores nas atividades desenvolvidas nesses espaços. Nessa categoria, 
enquadra-se a contribuição de Longhi e Schroeder (2012), que analisa as concepções de sete professores coordenadores das atividades de Clubes de Ciências em Blumenau/Santa Catarina (SC) sobre a natureza do conhecimento científico e as razões para a existência de Clubes de Ciências. De forma semelhante, Buch e Schroeder (2013) apresentam as concepções de cinco professores sobre abordagens metodológicas e avaliação em Clubes de Ciências.

A literatura sobre Clubes de Ciências ainda apresenta trabalhos com foco na formação inicial de professores, como o artigo de Parente, Teixeira e Saboia (2013), em que licenciandos em Química realizaram atividades de experimentação investigativa com alunos de ensino básico em um Clube de Ciências. Os autores analisam episódios em que ocorrem planejamento e desenvolvimento de investigação de forma coletiva entre os alunos de ensino básico (sexto e sétimo anos) auxiliados pelos licenciandos. As atividades eram parte do processo de formação desses futuros docentes. Os dados analisados basearam-se nas transcrições dos diálogos entre os participantes das atividades.

No trabalho de Baptista e colaboradores (2014), analisam-se as concepções de alunos do Programa Institucional de Bolsas de Iniciação à Docência (PIBID) Química da Universidade de Brasília (UnB) que trabalharam com Clubes de Ciências. Os autores observam que as respostas dos licenciandos a questionários mostram que o PIBID incentivou esses alunos a seguirem a carreira docente, além de encorajá-los a fomentar experiências metodológicas inovadoras na escola. Esses autores também destacam que os licenciandos que participaram dessas atividades têm experiências que o estágio curricular supervisionado pode não proporcionar em função da quantidade e qualidade das atividades realizadas.

É importante também citar como exemplo o trabalho de Adriano e Schroeder (2015), com licenciandos de Biologia que realizaram atividades de Clubes de Ciências em escolas municipais de Blumenau (SC). Nesse caso, os autores coletaram dados na forma de questionários com os licenciandos, que mostraram suas compreensões de ciência e a contribuição do projeto para sua formação profissional.

Em geral, professores apresentam uma visão exclusivamente empírica de Ciências (BECKER, 2005), dificultando a implementação de práticas educacionais inovadoras. O Clube de Ciências pode motivar os alunos de licenciatura a buscarem o aprimoramento da sua formação, com a integração da teoria e prática na educação em Ciências, indo ao encontro também da prática crítico-reflexiva (NÓVOA, 1992). Nesse sentido, o docente deve refletir sobre sua prática de modo crítico e estar disposto a melhorá-la para o enfrentamento de problemas vivenciados em situações próprias do dia a dia da escola (SILVA; SCHNETZLER, 2008).

Os trabalhos sobre Clubes de Ciências disponíveis na literatura em Educação em Ciências evidenciam que as atividades realizadas com base nesses princípios também contribuem de forma relevante nos processos de ensino e aprendizagem. Também é possível afirmar que esse tema é utilizado como base para pesquisas sobre processos de ensino e aprendizagem de alunos do ensino básico, na formação inicial de professores e ainda sobre as concepções de professores de Ciências da Natureza. No presente relato, temos como foco o papel de um Clube de Ciências na formação inicial de professores de Química. A seguir, 
apresentamos o referencial teórico que utilizaremos como base para a discussão dos dados.

\section{Interação}

Neste artigo, utilizamos elementos teóricos das contribuições de James Wertsch (1998) para a Educação em Ciências. A escolha desse referencial possibilita compreender as atividades realizadas em Clubes de Ciências do ponto de vista das ferramentas culturais ou meios mediacionais ali presentes. Nesse referencial teórico, todos os participantes (alunos do ensino básico, graduandos em licenciatura ou professores) podem ser considerados como agentes-agindo-com-ferramentas-culturais, e inclui a mediação viabilizada pelas ferramentas culturais. Esses elementos possibilitam entender os diversos tipos de ações que ocorrem em atividades de ensino de um ponto de vista sociocultural, em que o conhecimento deve ser visto como histórico e socialmente constituído, e não apenas individual (GIORDAN, 2008).

Esse referencial teórico possibilita colocar em evidência uma série de aspectos que integram interação e uso da linguagem nas pesquisas em Educação em Ciências. Silva e Chiaro (2018) observam a importância de interações dialógicas, em que há espaço para negociação, reelaboração de significados e interação. Em oposição a esse tipo de interação, há a função unívoca da linguagem, o que resulta em contato mínimo de vozes. Para além da linguagem falada, as habilidades de escrita e compreensão de texto também podem ser entendidas dentro do referencial apresentado, particularmente no caso de estudantes de licenciatura em Química (ROUAUX et al., 2006).

A partir do uso social da linguagem, há também estudos com esse referencial teórico que mostram a importância das emoções desencadeadas em função das interações sociais. Nesse caso, o professor precisa estar consciente dos resultados emocionais de suas interações sociais com os alunos como forma de aperfeiçoar os recursos didáticos mobilizados em sala de aula (MONTEIRO; GASPAR, 2007).

Ainda dentro das possíveis contribuições que as reflexões de Wertsch (1998) possibilitam para a área da Educação em Ciências, as interações verbais que ocorrem entre professor e alunos, ou entre alunos, podem revelar o interesse em aprender determinado tema. É nesse sentido que devemos valorizar e privilegiar os questionamentos feitos pelos estudantes, uma vez que o fator mais influente nesse caso é a elaboração da pergunta pelo aluno, e não o tipo de pergunta que é feita (GALLE; PAULETTI; RAMOS, 2016). Para além de perguntas, colaboram para sua aprendizagem atividades de planejamento de ensino em geral que são elaboradas pelos próprios estudantes de licenciatura, já que expressam preocupação com o domínio dos conteúdos e o conhecimento dos fenômenos envolvidos (LARA; DUARTE, 2018).

Potencializar a interação entre participantes das atividades de ensino é relevante, sob perspectiva sociocultural, na medida em que possibilita situações colaborativas, especialmente no ensino superior. Essas atividades promovem momentos de produção de 
fala, no sentido de perceber a influência da fala do interlocutor nas palavras do sujeito em foco (DUARTE; REZENDE, 2008). No caso de alunos que se envolvem na resolução de problemas em pequenos grupos, o seu engajamento nas discussões e o seu trabalho coletivo também já foram investigados com esse referencial teórico (REPICE et al., 2016), inclusive no sentido de sondar formas dialógicas ou de autoridade no discurso (AMARAL; MORTIMER, 2004).

Considerando os processos de ensino que ocorrem em um Clube de Ciências, há uma potencialização das interações verbais e não verbais entre alunos do ensino básico, licenciandos e professores. Nesse espaço é possível valorizar as perguntas feitas pelos estudantes como forma de participação e envolvimento afetivo e cognitivo com o tema. $\mathrm{O}$ engajamento dos envolvidos na resolução de problemas com uso da linguagem pode ser ainda mais potencializado com a escolha apropriada de ferramentas culturais, as quais descrevemos a seguir.

\section{Ferramenta cultural}

A concepção de ferramenta cultural é também bastante importante na Educação em Ciências nos diversos trabalhos já publicados com base no referencial teórico de James Wertsch (1998). Por exemplo, destaca-se a fala como uma macro-ferramenta cultural central para o ensino, já que é por intermédio da fala que o professor estabelece interlocução com os alunos e procura executar grande parte das atividades de ensino em sala de aula (GIORDAN, 2008).

Para Pinheiro (2012), a utilização de diferentes atividades de ensino, como ferramentas culturais, no planejamento de alunos de licenciatura em Química, é muito importante tanto para a formação inicial dos alunos de licenciatura quanto para os alunos de ensino básico que realizarão essas atividades. Nesse caso, as concepções de Wertsch (1998) permitem entender esse processo em cenários socioculturais definidos, o que promove a internalização do conhecimento (PINHEIRO, 2012).

Giordan, Silva-Neto e Aizawa (2015) baseiam-se nesse referencial para compreender a aprendizagem de alunos de licenciatura em Química, considerando as representações químicas e os gestos utilizados por estudantes na aprendizagem conceitual. Vilas Boas e Barbosa (2011) investigam como são produzidos discursos por parte de alunos por meio de manipulação de materiais e observam que os meios e a mediação estão profundamente imbricados.

Trazzi e Oliveira (2016) citam como exemplos de ferramentas culturais: livros, experimentos e gêneros discursivos, e observam que diversos contextos podem influenciar ou mesmo determinar a construção de conceitos. Com isso, tanto ferramentas culturais técnicas, como artefatos manipuláveis e atividades experimentais, além dos próprios discursos apresentados pelo professor, podem ser considerados como ferramentas culturais. Outros exemplos de ferramentas culturais que figuram na literatura de Educação em Ciências 
incluem plataformas digitais (MASSI; GIORDAN, 2014) ou mesmo programas computacionais interativos (DUARTE; REZENDE, 2008).

Neste estudo objetivamos relatar como licenciandos em Química descrevem as contribuições que a participação em um Clube de Ciências forneceu para sua formação inicial, especialmente considerando as ferramentas culturais utilizadas e as interações possibilitadas.

\section{Metodologia}

Os dados apresentados neste relato são discutidos a partir de um delineamento qualitativo, em que se procura compreender relações entre o sujeito e o mundo que não podem ser descritas por números (ALVES-MAZZOTTI; GEWANDSZNAJDER, 1999).

\section{Contexto da pesquisa}

$\mathrm{O}$ relato aqui apresentado refere-se às atividades de ensino e aprendizagem realizadas em um Clube de Ciências de uma escola pública localizada em São José do Rio Preto, interior do estado de São Paulo. As atividades do Clube de Ciências ocorreram quinzenalmente de maio a dezembro de 2017, com um total de 16 encontros. Participaram das atividades do Clube de Ciências um grupo de graduandos de licenciatura em Química de uma universidade pública, um grupo de alunos de ensino médio da escola e o professor responsável pela disciplina de Química da escola. Os alunos da escola parceira tinham entre 16 e 18 anos e as atividades contaram com a participação de cerca de 20 alunos a cada reunião do Clube de Ciências.

A participação dos alunos de licenciatura nas atividades do Clube de Ciências centrou-se em dois aspectos. $\mathrm{O}$ primeiro aspecto foi a preparação de materiais de apoio aos experimentos realizados no laboratório da escola. O segundo foi o acompanhamento das atividades experimentais, realizadas pelos alunos de Ensino Médio, por meio de questionamentos e discussões com conteúdo científico e as relações com a sociedade, as tecnologias e o ambiente. Os temas abordados nos encontros do Clube de Ciências foram eletroquímica, fluidos não-newtonianos, polímeros, misturas e solubilidade e as atividades foram realizadas no contraturno das aulas dos alunos de ensino médio.

\section{Sujeitos da pesquisa}

Os sujeitos desta pesquisa são três alunos de um curso de licenciatura em Química de uma universidade pública localizada no interior do estado de São Paulo. O curso é ministrado em período integral, oferece as modalidades de bacharelado e licenciatura com entrada única para todos os ingressantes e tem duração mínima de quatro anos em qualquer das 
modalidades. Os alunos matriculados escolhem uma das modalidades no segundo ano do curso. Os sujeitos da pesquisa cursavam o último ano da modalidade licenciatura.

Nessa modalidade, as disciplinas de fundamentos da Educação são ministradas a partir do segundo ano do curso e as disciplinas específicas sobre Educação em Química a partir do terceiro. As idades dos alunos de licenciatura em Química, ao finalizarem as atividades no Clube de Ciências, eram entre 23 e 24 anos. Seus nomes foram omitidos neste relato por questões éticas, de forma que os identificamos apenas com letras (A, B e C). A coleta de dados foi realizada após explicação da pesquisa, leitura e assinatura de termo de consentimento por parte dos licenciandos.

\section{Planejamento das atividades do Clube de Ciências}

Além de atuarem nas atividades do Clube de Ciências na escola parceira, os licenciandos participaram também de encontros quinzenais na universidade para a discussão, reflexão e planejamento das atividades feitas na escola. Compareceram a esses encontros o coordenador do projeto, os três licenciandos sujeitos da pesquisa e outro aluno do mesmo curso de Química que prestou apoio na organização e elaboração das atividades.

Os alunos de ensino médio da escola parceira também participaram do planejamento das atividades realizadas no Clube de Ciências. A primeira reunião do Clube foi destinada a um planejamento, em que se definiu como a divulgação seria feita na escola (pelos próprios alunos da escola), as metas do Clube (os alunos da escola preferiram apresentar uma feira de Ciências no final do ano letivo), sugestões de experimentos e temas por parte dos alunos de ensino médio, definição das datas dos encontros e dias da semana para as atividades. Da segunda reunião em diante foram realizadas as atividades de experimentação investigativa e problematizadora.

\section{Produção de dados}

Os dados apresentados neste estudo foram obtidos por meio de relatos dos alunos de licenciatura em Química que participaram da elaboração e aplicação das atividades realizadas no Clube de Ciências. Ao final do ano letivo, após a finalização das atividades do Clube de Ciências e apresentação da feira de Ciências na escola parceira, os alunos de licenciatura em Química apresentaram relatos orais e escritos sobre as atividades desenvolvidas.

Os relatos escritos foram elaborados pelos sujeitos dessa pesquisa após a apresentação de relatos orais na forma de seminários em duas ocasiões distintas: uma para outros alunos de licenciatura em Química e outra para professores da rede pública estadual de ensino. Essa trajetória possibilita aos sujeitos organizarem suas ideias ao expressarem suas experiências na forma de narrativas (LARROSA, 1996). 
$\mathrm{Na}$ análise dos dados, foram utilizados os princípios da Análise do Conteúdo (BARDIN, 2011), que incluiu pré-análise, exploração extensiva do material e tratamento dos resultados. Neste relato os dados apresentados são agrupados em três categorias, as quais são "Ferramentas Culturais" e "Impacto na formação do licenciando", definidas a priori, e a categoria "Alunos do Ensino Básico" emergente.

A principal ferramenta cultural utilizada nas atividades do Clube de Ciências foi a experimentação, uma vez que a maior parte das atividades elaboradas e realizadas foram experimentais. Em atividades de Clubes de Ciências, os aspectos tipicamente científicos de uma ferramenta cultural podem ser exercitados pelos alunos de ensino básico, e os aspectos relativos aos saberes docentes, por sua vez, podem ser exercitados por licenciandos ao planejarem e executarem as atividades. Nesse sentido, a mesma ferramenta cultural pode ser exercitada em seus aspectos científicos e didáticos, considerando os alunos de ensino básico e licenciandos. Em especial, foram utilizadas a experimentação problematizadora (DELIZOICOV, 1983) e a experimentação investigativa (HOFSTEIN et al., 2005).

\section{Resultados e discussão}

Os licenciandos, ao participarem do planejamento de atividades de ensino para serem aplicadas no Clube de Ciências, estiveram em busca do conhecimento científico contextualizado ao cotidiano dos alunos. Também se demonstraram atenciosos com os interesses e com as dificuldades dos alunos de Ensino Básico e buscavam sanar suas dúvidas, mesmo que em encontros posteriores.

Quando os licenciandos tinham dúvidas sobre o que fazer em determinadas situações nas atividades de ensino, o coordenador e o professor responsável pela disciplina de Química eram consultados e se discutia o tema nas reuniões quinzenais na universidade. Eles buscavam informações científicas sobre os experimentos e também a melhor forma de abordar os conhecimentos científicos, procurando sempre os aspectos centrais das concepções no experimento e as aplicações cotidianas, possibilitando conexões entre elas.

Os licenciandos também procuraram utilizar expressões cotidianas dos alunos de ensino básico com o objetivo de tornar o ambiente informal. Isso foi feito com a expectativa de diferenciar esse ambiente das atividades diárias da sala de aula, deixando-os mais à vontade. Com isso, houve a preocupação dos licenciandos em buscar melhorar sua interação com os estudantes. Essa experiência poderá refletir na sala de aula quando o licenciando se tornar um profissional e atuar diariamente nas escolas.

A seguir são apresentados e discutidos os resultados agrupados por categorias, bem como os excertos de relatos que as exemplificam. 
A delimitação dessa categoria tem a intenção de mostrar a intensidade do impacto que as atividades realizadas tiveram na formação dos licenciandos, na própria perspectiva deles. De fato, solicitou-se que os licenciandos escrevessem sobre qual papel as atividades no Clube de Ciências desempenharam em sua formação. Com isso, esperava-se que os relatos contivessem esse tópico, conforme vemos no quadro abaixo:

Quadro 1. Excertos dos relatos dos alunos de licenciatura agrupados na categoria "Impacto na formação do licenciando".

A: "O impacto que o Clube de Ciências teve em minha prática pedagógica foi intensa e interessante, não apenas por procurar estabelecer relações entre prática e teoria, em relação aos conteúdos, mas também por instigar a mim, como educador, procurar práticas visando a experimentação investigativa e problematização".

B: "Participar das atividades do clube de ciências como Professora em formação proporcionou-me inúmeras experiências que certamente irão contribuir em minhas práticas pedagógicas como docente formada".

C: "A participação no Clube de Ciências é a oportunidade de trabalhar e desenvolver diferentes metodologias e abordagens".

Fonte: Elaborado pelos autores.

É possível observar nos excertos dos relatos dos alunos A e B evidências de entusiasmo ao descreverem o papel das atividades para sua formação docente, conforme grifos acrescentados. Em especial, para o aluno A essa foi a primeira oportunidade de participar de atividades em um Clube de Ciências. O aluno B já participava pelo terceiro ano consecutivo de atividades desse tipo.

Já o aluno C, com uma descrição mais racional, participava de projetos envolvendo especificamente atividades de Clubes de Ciências pelo quarto ano consecutivo. É interessante observar que a descrição da intensidade do impacto por parte desses licenciandos é inversamente proporcional ao tempo que eles participam de atividades em Clubes de Ciências.

Pode-se entender que a menor intensidade na descrição do aluno $\mathrm{C}$ indica que as atividades realizadas já haviam se tornado comuns e cotidianas. Contudo, esse fato não reflete uma falta de entusiasmo pela realização das atividades, uma vez que esse aluno atuou de maneira exemplar.

Se considerarmos que os impactos apontados têm relação com o estado emocional dos licenciandos, os relatos agrupados nessa categoria estão em consonância com os resultados obtidos por Monteiro e Gaspar (2007), citado na introdução, em que são considerados os resultados emocionais dos alunos na interação com os professores. No caso dos licenciandos, que são alunos, mas que exercem algumas atividades típicas da docência no Clube de Ciências, há impactos emocionais positivos também nos futuros docentes. Como alunos que escolheram um curso superior em razão de seu interesse por Química, eles se sentem positivamente emocionados ao elaborarem e aplicarem atividades que percebem ser de 
proveito para os alunos de ensino básico. Também está em acordo com os resultados obtidos no estudo de Adriano e Schroeder (2015), em que licenciandos relatam com entusiasmo a contribuição do projeto para sua formação profissional.

\section{Alunos de ensino básico}

Nessa categoria apresentamos as concepções dos licenciandos sobre o porquê de as atividades do Clube de Ciências serem importantes para os alunos de ensino básico, no quadro abaixo:

Quadro 2. Excertos dos relatos dos alunos de licenciatura agrupados na categoria "Alunos de ensino básico".

A: "Acredito que o Clube possui sua importância por trazer, fora de aula, uma tentativa de aproximar o educando de um conhecimento mais científico e também a possibilidade de estimular a sua autonomia ao procurar estimular a sua curiosidade de um ponto de vista crítico, em busca pelo conhecimento".

B: "Dentre elas, a principal é a relação professor-aluno que se cria, pois participar do clube auxiliou-me a estabelecer uma relacão mais próxima com os alunos e em como estabelecer essa relação. Isso porque as atividades do clube são bem dinâmicas, permitindo muitos momentos de diálogos e discussões sobre os temas abordados".

C: "Outra diferença é a relação dos alunos com este espaço, pois por se tratar de uma atividade extracurricular, a grande maioria dos participantes, manifestam muito interesse pela ciência".

Fonte: Elaborado pelos autores.

Nos excertos agrupados nessa categoria, os licenciandos atribuem um grande valor ao relacionamento entre professores e alunos. Ao escreverem sobre porque o Clube foi importante para os alunos de ensino básico, todos apontaram fatores referentes à relação entre professores e alunos. O licenciando A indica a possibilidade de estimular seus alunos em conhecimentos mais científicos, além de autonomia e curiosidade, que se aproxima de uma direção freireana de conhecimento e está de acordo com as premissas da experimentação problematizadora (DELIZOICOV, 1983).

O licenciando B trata diretamente de estabelecer relação mais próxima com os alunos. Considerando que esse licenciando já estava realizando atividades em projetos de Educação em Química há 3 anos, é possível entender que, nessa modalidade de atividade de ensino, o licenciando sentiu mais possibilidades de estabelecer diálogos, além de discussões mais profícuas com os alunos.

Já o licenciando $\mathrm{C}$ aponta que os alunos, em atividades de Clubes de Ciências, apresentam muito interesse pela Ciência. Considerando que as atividades do Clube de Ciências eram eletivas, é possível compreender que apenas alunos interessados se inscreveram para as atividades. Nesse caso, evidencia-se que o maior interesse por parte dos alunos remete à interações mais proveitosas entre os participantes.

Os relatos agrupados nessa categoria também estão em acordo com os obtidos na literatura, que mostram a importância das interações dialógicas (ROUAUX et al., 2006) 
como elementos nas atividades de ensino. Da mesma forma, o tipo de interação verbal pode revelar o interesse em aprender (GALLE; PAULETTI; RAMOS, 2016), especialmente quando os alunos elaboram perguntas (LARA; DUARTE, 2018). De forma semelhante, as situações colaborativas, como é o caso das atividades experimentais no Clube de Ciências, têm papel preponderante no exercício dessa ferramenta cultural (DUARTE; REZENDE, 2008).

\section{Ferramentas Culturais}

Nesta categoria, agrupamos os trechos dos relatos em que os licenciandos se referiram aos conhecimentos pedagógicos, ou ferramentas culturais, necessários para elaborar e aplicar as atividades de experimentação no Clube de Ciências.

Quadro 3. Excertos dos relatos dos alunos de licenciatura agrupados na categoria "Ferramentas culturais".

A: "Acredito que, com as atividades semanais, a possibilidade de propor atividades problematizadoras ou investigativas teriam maior sucesso. O último ponto seria uma necessidade de buscar estabelecer relacões entre os conteúdos em sala de aula".

B: "Nesse sentido, eu atuando como professora no clube tive que estar em um frequente diálogo com os alunos, e isso me deixou muito próxima deles e também soube considerar mais suas opiniões para preparar as atividades. Além disso, a minha participação no clube ajudou-me a contextualizar mais os temas estudados e a deixá-los menos segmentados".

C: "Sendo assim, a abordagem, as questões, e as dúvidas apresentadas pelos alunos, proporcionam-nos a oportunidade de trabalhar a Química sob uma perspectiva mais científica, e portanto, tanto os alunos, como nós, crescemos muito durante o processo".

Fonte: Elaborado pelos autores.

O licenciando A observa que gostaria de fazer as atividades com frequência semanal, ao invés de quinzenal. Também observa que seria melhor se houvesse maior consonância com as atividades de sala de aula dos alunos. Nesse sentido, há a percepção de que seria melhor que os temas das atividades no Clube de Ciências coincidissem com aqueles trabalhados no planejamento anual da disciplina de Química ao invés de terem elaborado outro planejamento mais próximo aos interesses dos alunos de ensino médio. Com isso, esse aluno percebe que o exercício da ferramenta cultural "experimentação" seria mais eficaz se esses dois aspectos fossem melhorados. As observações escritas por A demonstram uma percepção de vontade de os alunos de ensino básico exercitarem a ferramenta cultural "experimentação" de forma mais intensa, mas também articulada com as outras atividades de ensino. Esse tipo de observação demonstra uma visão pedagógica mais amadurecida sobre a aprendizagem com a experimentação.

O licenciando B escreve que sua interação com os alunos o ajudou a levar em consideração os conhecimentos prévios ao preparar as atividades de ensino. Além disso, observa que conseguiu contextualizar e articular melhor os temas nas atividades do Clube de Ciências. Nesse sentido, há a percepção de que o uso da ferramenta cultural 
"experimentação" é potencializado quando se tem familiaridade com conhecimentos prévios dos alunos de ensino básico. Esse licenciando também tem a percepção que as atividades no Clube de Ciências o incentivaram a buscar maior conexão entre a Química e o contexto dos alunos de ensino básico, o que tornaria o conteúdo menos segmentado. Com isso, os temas trabalhados nas atividades do Clube de Ciências têm maior potencial de serem compreendidos como um todo e parte do cotidiano dos alunos de ensino básico.

Em outra direção, o licenciando $\mathrm{C}$ escreve que conseguiu trabalhar o tema de maneira mais científica em função da melhor interação com os alunos de ensino básico. A compreensão dos aspectos científicos centrais para os conteúdos escolares tem sido um desafio na Educação em Ciências (SILVA; QUEIROZ, 2017). A percepção desse estudante de licenciatura é de que as ferramentas culturais exercitadas no Clube de Ciências possibilitam um ambiente de interação que viabiliza uma melhor abordagem dos conteúdos, de forma que os aspectos científicos sejam trabalhados coerentemente.

Diante das percepções apresentadas nos excertos do quadro 3, é possível entender que esses licenciandos exercitaram um uso didático da ferramenta cultural "experimentação" nas atividades do Clube de Ciências, o que está em acordo com saberes docentes que contribuirão para interações dialógicas em que há espaço para negociação e reelaboração de significados.

\section{Considerações finais}

É possível observar a importância formativa dessa experiência para os licenciandos que participaram das atividades no Clube de Ciências. Os dados mostram que as atividades do Clube de Ciências incentivaram esses alunos de licenciatura em Química a refletirem sobre a sua prática docente e a melhorá-la, conforme as observações que obtiveram dos alunos de ensino básico participantes das atividades. As categorias de análise apresentadas, "Impactos na formação do licenciando", "alunos de ensino básico" e "ferramentas culturais", auxiliaram a descrever melhor a experiência que as atividades do Clube de Ciências tiveram na formação desses licenciandos em Química.

Primeiramente, descrevemos a percepção dos licenciandos sobre os impactos positivos que as atividades no Clube de Ciências tiveram em sua formação inicial. Na perspectiva sociocultural adotada, os impactos apontados sobre os estados emocionais são importantes na formação de professores, uma vez que se sentem positivamente emocionados ao elaborarem e aplicarem as atividades no Clube de Ciências.

Em seguida, apontamos como os licenciandos perceberam sua interação com os alunos de ensino básico. Os dados mostraram que os licenciandos indicaram como elementos nessa relação a possibilidade de estimular seus alunos, o potencial de autonomia e curiosidade, a oportunidade de estabelecer relação mais próxima com os alunos, a potencialidade de estabelecer diálogos, além de discussões mais profícuas com os alunos. Ademais, os licenciandos observaram que os alunos de ensino básico, em atividades de 
Clubes de Ciências, apresentam muito interesse pelo tema. Em função desse tipo de situação colaborativa, há melhoria qualitativa na interação verbal.

Também foi possível observar que, na percepção dos licenciandos, o exercício da ferramenta cultural "experimentação" seria mais eficaz se as atividades do Clube de Ciências fossem realizadas com maior frequência semanal e com maior proximidade com as atividades de sala de aula. Além disso, a "experimentação" é potencializada quando levados em consideração os conhecimentos prévios dos estudantes ao preparar as atividades de ensino, o que incentiva os licenciandos a contextualizar melhor as atividades. Também há a percepção por parte dos licenciandos de que o exercício dessa ferramenta cultural no Clube de Ciências possibilita uma abordagem mais científica dos temas tratados.

Em nosso estudo, partimos do pressuposto que as atividades de Clubes de Ciências são um exemplo sobre como contextos de ensino específicos influenciam o desenvolvimento de saberes docentes de professores de Química em formação inicial. É importante destacar que a apropriação da ferramenta cultural "experimentação" por parte de futuros professores de Química é absolutamente central, uma vez que se trata de um profissional que ensinará a estudantes de ensino básico os principais conhecimentos que fundamentam a prática científica. Nesse sentido, recomendamos o uso de atividades de ensino no formato de Clubes de Ciências como parte da formação inicial de professores de Química, pois possibilitam vivências singulares em atividades de ensino e aprendizagem.

\section{Referências}

ADRIANO, Graciele Alice Carvalho; SCHROEDER, Edson. Compreensões dos bolsistas de iniciação à docência/PIBID sobre Clubes de Ciências, ciência e o seu processo de formação inicial. Revista Brasileira de Ensino de Ciência e Tecnologia. Ponta Grossa, v. 8, n. 2, p. 101-114, jan./abr. 2015.

ALVES, José Moysés et al. Sentidos subjetivos relacionados com a motivação dos estudantes do Clube de Ciências de Ilha de Cotijuba. Revisa Ensaio. Belo Horizonte, v. 14, n. 3, p. 97110, set./dez. 2012.

ALVES-MAZZOTTI, Alda Judith; GEWANDSZNAJDER, Fernando. O método nas ciências naturais e sociais: pesquisa quantitativa e qualitativa. 2 ed. São Paulo: Pioneira, 1999.

AMARAL, Edenia María Ribeiro; MORTIMER, Eduardo Fleury. Un perfil conceptual para entropía y espontaneidad: una caracterización de las formas de pensar y hablar en el aula de química. Educación Química. México, v. 15, n. 1, p. 218-233, jul./sept. 2004.

BAPTISTA, Joice de Aguiar et al. PIBID/Licenciatura em Química da Universidade de Brasília: inter-relacionando ensino, pesquisa e extensão. Química Nova na Escola. São Paulo, v. 36, n. 1, p. 18-27, fev. 2014.

BARDIN, Laurence. Análise de conteúdo. São Paulo: Edições 70, 2011. 
BECKER, Fernando. A epistemologia do professor: o cotidiano da escola. 12 ed. Petrópolis: Vozes, 2005.

BUCH, Gisele Moraes; SCHROEDER, Edson. Clubes de Ciências e alfabetização científica: concepções dos professores coordenadores da rede municipal de ensino de Blumenau (SC).

Experiências em Ensino de Ciências. Cuiabá, v. 8, n. 1, p. 72-86, abr. 2013.

COLOMBO JUNIOR, Pedro Donizete. Enfim Professor. E agora? Alexandria.

Florianópolis, v. 2, n. 1, p. 27-44, mar. 2009.

DELIZOICOV, Demétrio. Ensino de Física e a concepção freiriana de educação. Revista de Ensino de Física. São Paulo, v. 5, n. 2, p. 85-98, dez. 1983.

DUARTE, Márcia; REZENDE, Flavia. Construção discursiva na interação colaborativa de estudantes com um sistema hipermídia de biomecânica. Revista Electrónica de Enseñanza de las Ciencias. Vigo, Espanha, v. 7, n. 2, p. 399-419, 2008.

GALLE, Lorita Aparecida Veloso; PAULETTI, Fabiana; RAMOS, Maurivan Güntzel. Pesquisa em sala de aula: os interesses dos estudantes manifestados por meio de perguntas sobre a queima da vela. Acta Scientiae. Canoas, v. 18, n. 2, p. 498-516, maio/ago. 2016.

GATTI, Bernadete Angelina. Formação de professores: condições e problemas atuais.

Revista Internacional de Formação de Professores. Itapetininga, v. 1, n. 2, p. 161-171, abr./jun. 2016.

GIORDAN, Marcelo. Computadores e linguagens nas aulas de Ciências: uma perspectiva sociocultural para compreender a construção de significados. 1 ed. Ijuí: Unijuí, 2008.

GIORDAN, Marcelo; SILVA-NETO, Arcelino Bezerra; AIZAWA, Alexandre. Relações entre gestos e operações epistêmicas mediadas pela representação estrutural em aulas de química e suas implicações para a produção de significados. Química Nova na Escola. São Paulo, v. 37, número especial 1, p. 82-94, jul. 2015.

HOFSTEIN, Avi et al. Developing students' ability to ask more and better questions resulting from inquiry-type chemistry laboratories. Journal of Research in Science Teaching, v. 42, n. 7, p. 791-806, 2005.

LARA, Moisés da Silva; DUARTE, Luciana Gili Vieira. A contextualização na formação de professores de química. ACTIO: Docência em Ciências. Curitiba, v. 3, n. 3, p. 173-196, set./dez. 2018.

LARROSA, Jorge. La experiencia de la lectura. Barcelona: Laertes, 1996.

LONGHI, Adriana; SCHROEDER, Edson. Clubes de ciências: o que pensam os professores coordenadores sobre ciência, natureza da ciência e iniciação científica numa rede municipal de ensino. Revista Electrónica de Enseñanza de las Ciencias. Vigo, Espanha, v. 11, n. 3, p. 547-564, 2012. 
MASSI, Luciana; GIORDAN, Marcelo. Introdução à pesquisa com sequências didáticas na formação continuada online de professores de ciências. Revista Ensaio. Belo Horizonte, v. 16, n. 3, p. 75-93, set./dez. 2014.

MONTEIRO, Isabel Cristina de Castro; GASPAR, Alberto. Um estudo sobre as emoções no contexto das interações sociais em sala de aula. Investigações em Ensino de Ciências. Porto Alegre, v. 12, n. 1, p. 71-84, mar. 2007.

NÓVOA, António. Formação de Professores e profissão docente. In: NÓVOA, António (coord.). Os professores e a sua formação. Lisboa, Dom Quixote, 1992. p. 13-33.

OLIVEIRA, Moisés Alves de. Alfabetização científica no Clube de Ciências do ensino fundamental: uma questão de inscrição. Revista Ensaio. Belo Horizonte, v. 12, n. 2, p. 1126, maio/ago. 2010.

PARENTE, Andrela Garibaldi Loureiro; TEIXEIRA, Odete Pacubi Baierl; SABOIA, Tiago Corrêa. A quantidade de milho influencia na proliferação de gorgulho? Aspectos teóricos que subsidiam o processo de construção de dados em uma investigação. Experiências em Ensino de Ciências. Cuiabá, v. 8, n. 2, p. 51-69, ago. 2013.

PARENTE, Andrela Garibaldi Loureiro et al. Fatores que influenciam a erosão na orla da UFPA: narrando percursos de uma investigação com alunos de séries iniciais no CCIUFPA. Experiências em Ensino de Ciências. Cuiabá, v. 5, n. 3, p. 123-130, dez. 2010.

PINHEIRO, Paulo César. Aumentando o interesse do alunado pela química escolar e implantação da nova proposta curricular mineira: desenvolvimento e resultados de projeto seminal realizado no PIBID-UFSJ. Química Nova na Escola. São Paulo, v. 34, n. 4, p. 173183, nov. 2012.

PRÁ, Grazieli de; TOMIO, Daniela. Clube de Ciências: condições de produção da pesquisa em educação científica no Brasil. Alexandria. Florianópolis, v. 7, n. 1, p. 179-207, maio 2014.

REPICE, Michelle et al. Talking through the problems: a study of discourse in peer-led small groups. Chemistry Education Research and Practice, v. 17, p. 555-568, 2016.

RIBEIRO, Carlos José Monteiro; PARENTE, Andrela Garibaldi Loureiro. A interferência da urbanização na sobrevivência das espécies de formigas: uma experiência com pesquisa no ensino de ciências. Experiências em Ensino de Ciências. Cuiabá, v. 1, n. 3, p. 33-44, dez. 2006.

ROUAUX, Ricardo et al. Una valoración de la comprensión lectora en alumnos del primer año de la universidad. Educacion Química. México, v. 17, n. 1, p. 77-81, 2006.

SANTOS, Flávia Maria Teixeira dos; MORTIMER, Eduardo Fleury. Estratégias e táticas de resistência nos primeiros dias de aula de química. Química Nova na Escola. São Paulo, n. 10, p. 38-42, nov. 1999. 
SCHLEICH, Álisson Passos et al. Educação ambiental em um Clube de Ciências, utilizando geotecnologias. Experiências em Ensino de Ciências. Cuiabá, v. 9, n. 2, p. 117-138, ago. 2014.

SILVA, Ana Carla da; CHIARO, Sylvia de. O impacto da interface entre a aprendizagem baseada em problemas e a argumentação na construção do conhecimento. Investigações em Ensino de Ciências. Porto Alegre, v. 23, n. 3, p. 82-109, dez. 2018.

SILVA, Osmair Benedito da; QUEIROZ, Salete Linhares. Produção acadêmica sobre a formação de professores de química no Brasil: focos temáticos das dissertações e teses defendidas no período de 2001 a 2010 . Alexandria. Florianópolis, v. 10, n. 1, p. 271-304, maio 2017.

SILVA, Patrícia do Socorro de Campos da; SANTOS, Sonia Barbosa dos; RÔÇAS, Giselle. A visão sobre a ciência e cientistas: explorando concepções em um clube de ciências. Revista Brasileira de Ensino de Ciência e Tecnologia. Ponta Grossa, v. 9, n. 3, p. 1-23, maio/ago. 2016.

SILVA, Rejane Maria Ghisolfi da; SCHNETZLER, Roseli Pacheco. Concepções e ações de formadores de professores de Química sobre o estágio supervisionado: propostas brasileiras e portuguesas. Química Nova. São Paulo, v. 31, n. 8, p. 2174-2183, 2008.

TARDIF, Maurice. Saberes docentes e formação profissional. Petrópolis, RJ: Vozes, 2002.

TRAZZI, Patricia Silveira da Silva; OLIVEIRA, Ivone Martins de. A ação mediada no processo de formação dos conceitos científicos de fotossíntese e respiração celular em aulas de biologia. Investigações em Ensino de Ciências. Porto Alegre, v. 21, n. 2, p. 121-136, ago. 2016.

VILAS BOAS, Jamille; BARBOSA, Jonei Cerqueira. Os materiais manipuláveis e a produção discursiva dos alunos na aula de matemática. Acta Scientiae. Canoas, v. 13, n. 2, p. 39-53, jul./dez. 2011.

WERTSCH, James. Mind as action. New York: Oxford Uni Press, 1998.

\section{Notas}

${ }^{\text {i }}$ Disponível em: https://catalogodeteses.capes.gov.br. Acesso em: 10 fev. 2019.

${ }^{\mathrm{i}}$ Disponível em: https://scholar.google.com.br. Acesso em: 10 fev. 2019.

\section{Agradecimentos}

Agradecemos à PROEx/UNESP pelo auxílio financeiro.

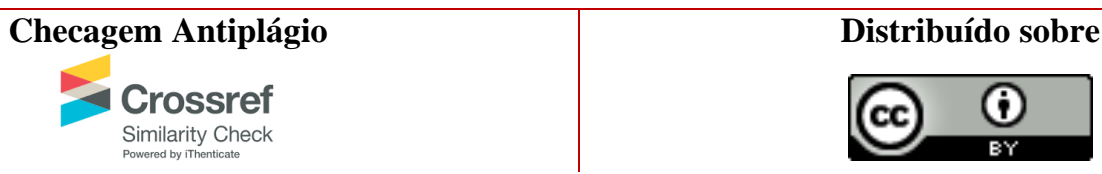

